\title{
RESEARCH ON THE GEOMETRY OF SPATIAL RACK DRIVES WITH FACE MATING MOVABLE LINKS \\ PART II. SYNTHESIS OF THE SURFACE OF ACTION OF THE LINK REALIZING RECTILINEAR TRANSLATION
}

\author{
Emilia Abadjieva \\ Graduate School of Engineering Science, \\ Faculty of Engineering Science, \\ Tegatagakuen machi 1-1, Akita, Japan \\ Institute of Mechanics, \\ Bulgarian Academy of Sciences, \\ Acad. G. Bonchev St., Bl. 4, 1113 Sofia, Bulgaria, \\ e-mail: abadjieva@gipc.akita-u.co.jp; abadjieva@gmail.com
}

\begin{abstract}
In this second part of the article, analytical dependencies, which define the basic geometric characteristics of the mesh region and the active tooth surfaces of the link realizing rectilinear translations, are presented. The cases, considered here, are when the active tooth surfaces of the rotating link are face convolute, Archimedean and involute helical surfaces with a constant pitch. These surfaces are analytically defined in Part I of this study.

Keywords: rack drives, mathematical modeling, synthesis, face linear helicoid, action surface, mesh region.
\end{abstract}

\section{INTRODUCTION}

The successful implementation in the technique of spatial rack drives with new kinematic and strength characteristics is held by the insufficient knowledge of the common principles of this transformation due to the lack of offered specific approaches to the mathematical modeling oriented to their synthesis.

The current study is dedicated to the synthesis of one new innovative type gear transmissions - spatial face rack drives [1]. This type of mechanisms serves to transform rotation of a face worm into a translational motion of a gear rack.

The face rack drives are innovative transmissions that are suitable for implementation into a precise compact mechanical systems with a small translational motion and with high smoothness and high loading capacity.

DOI: 10.7546/EngSci.LV.18.01.02

(c) Инженерни науки, год. LV, 2018, № 1

20

(c) Engineering Sciences, LV, 2018, No. 1 


\section{SYNTHESIS OF SPATIAL FACE LINEAR MECHANISMS}

\subsection{Face convolute rack mechanism}

The synthesis of the studied type rack drive is accomplished in accordance with the second principle of T. Olivier [1,2], when the symbols given in Fig. 1 are taken under consideration. In connection with the current study, the equations system (1) and (2) of the active surfaces $\Sigma_{f}^{(j)} \equiv \Sigma_{1}^{(j)}(j=1,2)$ and the normal vector $\bar{n}_{f}$ (of the face convolute worm) to them, written in their co-ordinate systems $S_{f}^{(j)}\left(O_{f}^{(j)}, x_{f}^{(j)}, y_{f}^{(j)}, z_{f}^{(j)}\right)$, are presented as follows [3]:

$$
\begin{aligned}
& x_{f}^{(j)}=r_{0} \cos \vartheta-U^{(j)} \sin \vartheta, \\
& y_{f}^{(j)}=r_{0} \sin \vartheta+U^{(j)} \cos \vartheta, \\
& z_{f}^{(j)}=\mp u^{(j)} \cos \xi^{(j)},
\end{aligned}
$$

where $U^{(j)}=u^{(j)} \sin \xi^{(j)}-p_{t} \vartheta$ and

$$
\begin{aligned}
& n_{f, x_{f}}^{(j)}= \pm \cos \xi^{(j)}\left(K \cos \vartheta-U^{(j)} \sin \vartheta\right), \\
& n_{f, y_{f}}^{(j)}= \pm \cos \xi^{(j)}\left(K \sin \vartheta+U^{(j)} \cos \vartheta\right), \\
& n_{f, z_{f}}^{(j)}=U^{(j)} \sin \xi^{(j)},
\end{aligned}
$$

where $K=r_{0}-p_{t}$.

The equations (1) and (2) are written in the fixed co-ordinate system $S(O, x, y, z)$, i.e.:

$$
\begin{gathered}
{\left[x^{(j)}, y^{(j)}, z^{(j)}, t=1\right]^{T}=M_{S S_{f}}\left[x_{f}^{(j)}, y_{f}^{(j)}, z_{f}^{(j)}, t_{f}=1\right]^{T},} \\
{\left[n_{f, x}^{(j)}, n_{f, y}^{(j)}, n_{f, z}^{(j)}\right]^{T}=L_{S S_{f}}\left[n_{f, x_{f}}^{(j)}, n_{f, y_{f}}^{(j)}, n_{f, z_{f}}^{(j)}\right]^{T},}
\end{gathered}
$$

where

$$
M_{S S_{f}}=\left\|\begin{array}{cccc}
\cos \varphi_{1} & -\cos \varphi_{1} & 0 & 0 \\
\sin \varphi_{1} & \cos \varphi_{1} & 0 & 0 \\
0 & 0 & 1 & 0 \\
0 & 0 & 0 & 1
\end{array}\right\|, \quad L_{S S_{f}}=\left\|\begin{array}{ccc}
\cos \varphi_{1} & -\cos \varphi_{1} & 0 \\
\sin \varphi_{1} & \cos \varphi_{1} & 0 \\
0 & 0 & 1
\end{array}\right\|
$$

whence

$$
\begin{aligned}
& x^{(j)}=r_{0} \cos \theta-U^{(j)} \sin \theta, \\
& y^{(j)}=r_{0} \sin \theta+U^{(j)} \cos \theta, \\
& z^{(j)}=z_{f}^{(j)}= \pm u^{(j)} \cos \xi^{(j)},
\end{aligned}
$$

(c) Инженерни науки, год. LV, 2018, № 1 
where $\theta=\vartheta+\varphi_{1}$,

$$
\begin{aligned}
& n_{f, x}^{(j)}= \pm \cos \xi^{(j)}\left(K \cos \theta-U^{(j)} \sin \theta\right), \\
& n_{f, y}^{(j)}= \pm \cos \xi^{(j)}\left(K \sin \theta+U^{(j)} \cos \theta\right), \\
& n_{f, z}^{(j)}=U^{(j)} \sin \xi^{(j)} .
\end{aligned}
$$

For the studied case the equation of meshing is written as [4-6]:

$$
\bar{n}_{f} \bar{V}_{12}=n_{f, x} V_{12, x}+n_{f, y} V_{12, y}+n_{f, z} V_{12, z}=0 .
$$

The sliding velocity vector $\bar{V}_{12}$ at an arbitrary contact point from the contact line $D_{12}^{(j)}$ between $\Sigma_{1}^{(j)}$ and $\Sigma_{2}^{(j)}$ is:

$$
\bar{V}_{12}=\left(-y+j_{21}\right) \bar{i}+x \bar{j}+0 . \bar{k},
$$

where $\bar{i}, \bar{j}, \bar{k}$ are unit vectors of the co-ordinate axis of $S(O, x, y, z) ; j_{21}-$ velocity ratio of the studied rack drive.

Then, from equations (5), (6), (7) and (8), the following type of the equation of meshing is obtained:

$$
U^{(j)}=\frac{K \cdot j_{21} \cos \theta}{j_{21} \sin \theta+p_{t}} .
$$

The action surface of the studied rack mechanism has the following analytical form, which is composed of the equations (5) and (9):

$$
\begin{aligned}
x^{(j)} & =r_{0} \cos \theta-U^{(j)} \sin \theta, \\
y^{(j)} & =r_{0} \sin \theta+U^{(j)} \cos \theta, \\
z^{(j)} & = \pm u^{(j)} \cos \xi^{(j)}, \\
U^{(j)} & =\frac{K \cdot j_{21} \cos \theta}{j_{21} \sin \theta+p_{t}} .
\end{aligned}
$$

The tooth surfaces $\Sigma_{2}^{(j)}(j=1,2)$ of the gear rack are determined by the equation systems:

$$
\begin{aligned}
& {\left[x_{2}^{(j)}, y_{2}^{(j)}, z_{2}^{(j)}, t_{1}=1\right]^{T}=M_{S_{2} S}\left[x^{(j)}, y^{(j)}, z^{(j)}, t=1\right]^{T},} \\
& n_{f, x_{2}} V_{12, x_{2}}+n_{f, y_{2}} V_{12, y_{2}}+n_{f, z_{2}} V_{12, z_{2}}=0, \\
& {\left[n_{f, x_{2}}, n_{f, y_{2}}, n_{f, z_{2}}\right]^{T}=L_{S_{2} S}\left[n_{f, x}, n_{f, y}, n_{f, z}\right]^{T},} \\
& {\left[V_{12, x_{2}}, V_{12, y_{2}}, V_{12, z_{2}}\right]^{T}=L_{S_{2} S}\left[V_{12, x}, V_{12, y}, V_{12, z}\right]^{T},}
\end{aligned}
$$

(C) Инженерни науки, год. LV, 2018, № 1 


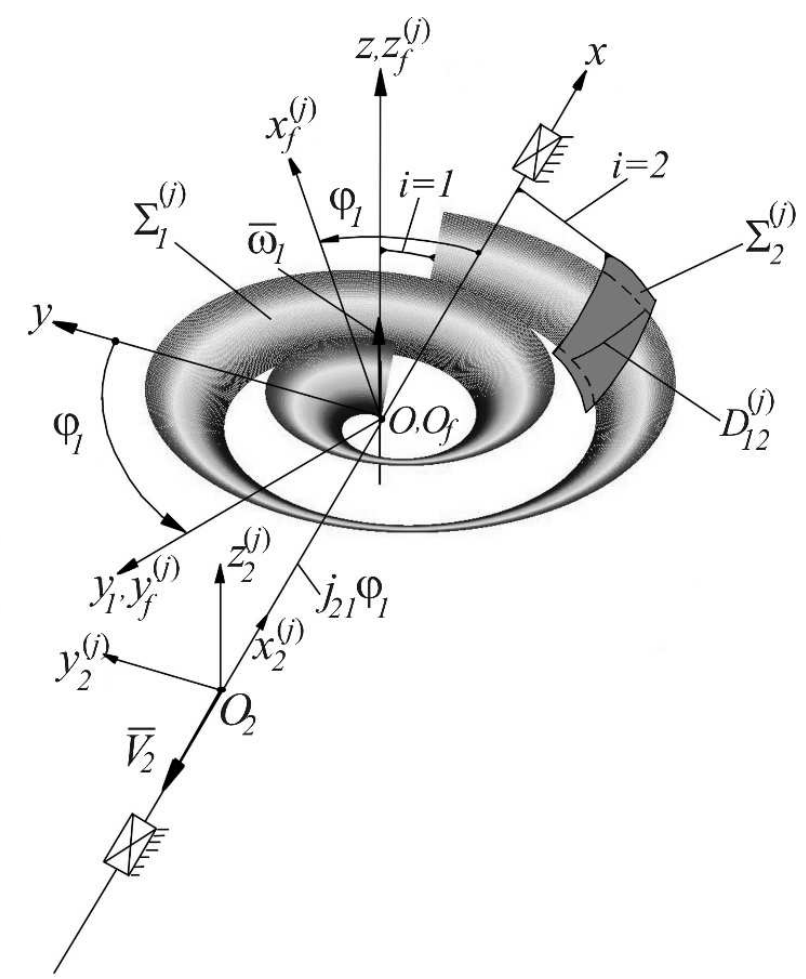

Fig. 1. Geometric-kinematic scheme of face rack-mechanism: $\Sigma_{1}^{(j)}$ is the face helicoid; $\Sigma_{2}^{(j)}$ - an active tooth surfaces of the tooth rack; $\bar{\omega}_{1}-$ velocity vector of the rotating link $i=1$ (face worm); $\bar{V}_{2}$ - velocity vector of the rectilinear translation of the link $i=2$ (gear rack); $S(O, x, y, z)$ - static co-ordinate system; $S_{f}^{(j)}\left(O_{f}^{(j)}, x_{f}^{(j)}, y_{f}^{(j)}, z_{f}^{(j)}\right)$ - co-ordinate system firmly connected with the link $i=1 ; S_{2}^{(j)}\left(O_{2}^{(j)}, x_{2}^{(j)}, y_{2}^{(j)}, z_{2}^{(j)}\right)$ - co-ordinate system firmly connected with the link $i=2 ; \varphi_{1}$ - meshing parameter

where

$$
M_{S_{2} S}=\left\|\begin{array}{cccc}
1 & 0 & 0 & j_{21} \varphi_{1} \\
0 & 1 & 0 & 0 \\
0 & 0 & 1 & 0 \\
0 & 0 & 0 & 1
\end{array}\right\|, \quad L_{S_{2} S}=E_{3 \times 3}
$$

The equations describing active tooth surfaces $\Sigma_{2}^{(j)}(j=1,2)$ are obtained, after transformation of equation (11):

(c) Инженерни науки, год. LV, 2018, № 1 


$$
\begin{aligned}
x_{2}^{(j)} & =r_{0} \cos \theta-U^{(j)} \sin \theta+j_{21} \varphi_{1}, \\
y_{2}^{(j)} & =r_{0} \sin \theta+U^{(j)} \cos \theta, \\
z_{2}^{(j)} & = \pm u^{(j)} \cos \xi^{(j)}, \\
U^{(j)} & =\frac{K \cdot j_{21} \cos \theta}{j_{21} \sin \theta+p_{t}}, \\
x^{(j)} & =r_{0} \cos \theta-U^{(j)} \sin \theta, \\
y^{(j)} & =r_{0} \sin \theta+U^{(j)} \cos \theta, \\
z^{(j)} & = \pm u^{(j)} \cos \xi^{(j)}, \\
U^{(j)} & =\frac{K \cdot j_{21} \cos \theta}{j_{21} \sin \theta+p_{t}} .
\end{aligned}
$$

The equations of active tooth surfaces $\Sigma_{2}^{(j)}(j=1,2)$ of the gear rack are determined by the system of equations:

$$
\begin{aligned}
& {\left[x_{2}^{(j)}, y_{2}^{(j)}, z_{2}^{(j)}, t_{1}=1\right]^{T}=M_{S_{2} S}\left[x^{(j)}, y^{(j)}, z^{(j)}, t=1\right]^{T},} \\
& n_{f, x_{2}} V_{12, x_{2}}+n_{f, y_{2}} V_{12, y_{2}}+n_{f, z_{2}} V_{12, z_{2}}=0, \\
& {\left[n_{f, x_{2}}, n_{f, y_{2}}, n_{f, z_{2}}\right]^{T}=L_{S_{2} S}\left[n_{f, x}, n_{f, y}, n_{f, z}\right]^{T},} \\
& {\left[V_{12, x_{2}}, V_{12, y_{2}}, V_{12, z_{2}}\right]^{T}=L_{S_{2} S}\left[V_{12, x}, V_{12, y}, V_{12, z}\right]^{T},}
\end{aligned}
$$

where

$$
M_{S_{2} S}=\left\|\begin{array}{cccc}
1 & 0 & 0 & j_{21} \varphi_{1} \\
0 & 1 & 0 & 0 \\
0 & 0 & 1 & 0 \\
0 & 0 & 0 & 1
\end{array}\right\|, \quad L_{S_{2} S}=E_{3 \times 3} .
$$

The equations of active tooth surfaces $\Sigma_{2}^{(j)}(j=1,2)$ are obtained from the system of equations (11):

$$
\begin{aligned}
x_{2}^{(j)} & =r_{0} \cos \theta-U^{(j)} \sin \theta+j_{21} \varphi_{1}, \\
y_{2}^{(j)} & =r_{0} \sin \theta+U^{(j)} \cos \theta, \\
z_{2}^{(j)} & = \pm u^{(j)} \cos \xi^{(j)} \\
U^{(j)} & =\frac{K \cdot j_{21} \cos \theta}{j_{21} \sin \theta+p_{t}} .
\end{aligned}
$$

(c) Инженерни науки, год. LV, 2018, № 1 

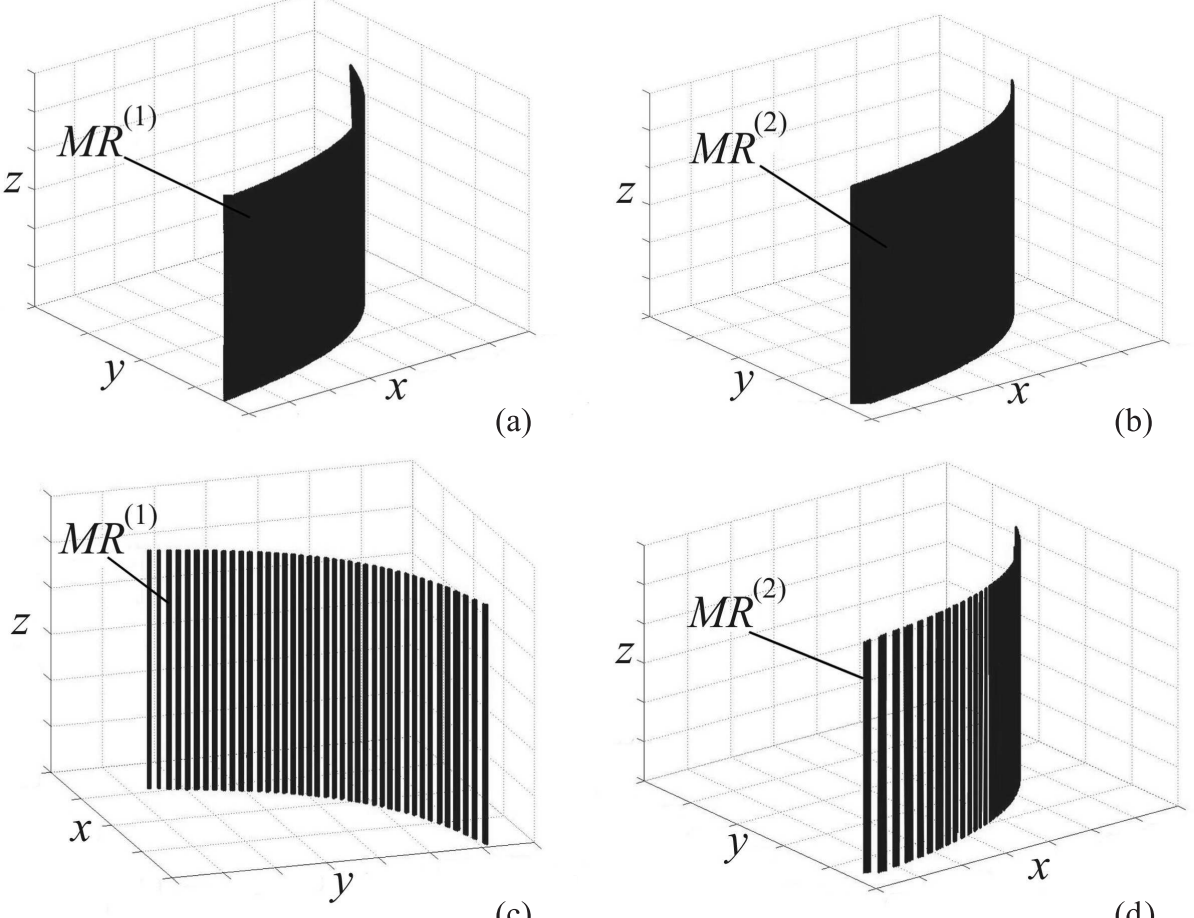

(c)

(d)
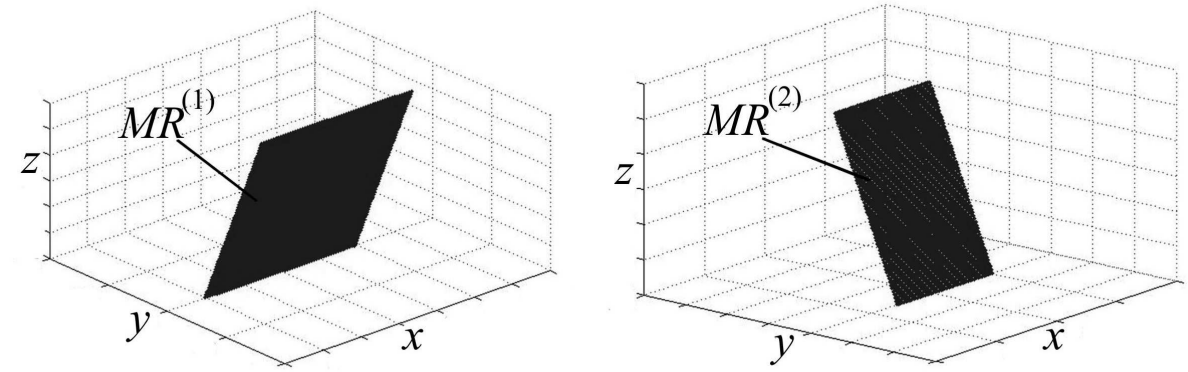

(e)

(f)

Fig. 2. Mesh surfaces $M R^{(1)}$ and $M R^{(2)}$ of spatial right face rack drives with velocity ratio $j_{21}=1.273 \mathrm{~mm} / \mathrm{rad}$ and with teeth number $z_{1}=1$ and parameters $\Sigma_{1}^{(1)} \Rightarrow \xi^{(1)}=150^{\circ}, u^{(1)} \in[0,6], \vartheta^{(1)} \in[4,8,8 \pi], \Sigma_{1}^{(2)} \Rightarrow \xi^{(2)}=120^{\circ}, u^{(2)} \in[0,6]$, $\vartheta^{(2)} \in[4,8,8 \pi]:$ (a) and (b) convolute $-r_{0}^{(1,2)}=10 \mathrm{~mm}$; (c) and (d) Archimedean; (e) and (f) involute $-r_{0}^{(1,2)}=10 \mathrm{~mm}$

Figure 2(a,b) shows the mesh region of face convolute rack drive.

(c) Инженерни науки, год. LV, 2018, № 1 


\subsection{Face Archimedean rack mechanism}

The analytical description of the action surface of face Archimedean rack mechanism is obtained from the system of equations (13), when substituting $r_{0}=0$ (whence $K=-p_{t}$ ), i. e.:

$$
\begin{aligned}
x^{(j)} & =-U^{(j)} \sin \theta, \\
y^{(j)} & =U^{(j)} \cos \theta, \\
z^{(j)} & = \pm u^{(j)} \cos \xi^{(j)}, \\
U^{(j)} & =-\frac{p_{t} \cdot j_{21} \cos \theta}{p_{t}+j_{21} \sin \theta} .
\end{aligned}
$$

From the system of equations (15) with analogical substitution, the analytical description of the tooth surfaces of the gear rack (conjugated with face Archimedean helicoids) is obtained:

$$
\begin{aligned}
x_{2}^{(j)} & =-U^{(j)} \sin \theta+j_{21} \varphi_{1}, \\
y_{2}^{(j)} & =U^{(j)} \cos \theta \\
z_{2}^{(j)} & = \pm u^{(j)} \cos \xi^{(j)} \\
U^{(j)} & =-\frac{p_{t} j_{21} \cos \theta}{j_{21} \sin \theta+p_{t}} .
\end{aligned}
$$

In Figure 2(c,d) the region of mesh of face Archimedean rack transmission is illustrated.

\subsection{Face involute rack mechanism}

The equations of mesh regions and the active tooth surfaces $\Sigma_{2}^{(j)}$ of the gear rack of face involute rack mechanism are obtained from systems (10) and (12) by taking into account the condition of enveloping of the face involute helicoid $K=0$, i.e.:

$$
\begin{aligned}
& x^{(j)}=r_{0} \cos \theta-U^{(j)} \sin \theta, \\
& y^{(j)}=r_{0} \sin \theta+U^{(j)} \cos \theta, \\
& z^{(j)}= \pm u^{(j)} \cos \xi^{(j)}, \\
& U^{(j)}\left(j_{21} \sin \theta+p_{t}\right)=0, U^{(j)} \neq 0,
\end{aligned}
$$

(C) Инженерни науки, год. LV, 2018, № 1 


$$
\begin{aligned}
& x_{2}^{(j)}=r_{0} \cos \theta-U^{(j)} \sin \theta+j_{21} \varphi_{1}, \\
& y_{2}^{(j)}=r_{0} \sin \theta+U^{(j)} \cos \theta, \\
& z_{2}^{(j)}= \pm u^{(j)} \cos \xi^{(j)}, \\
& U^{(j)}\left(j_{21} \sin \theta+p_{t}\right)=0, U^{(j)} \neq 0 .
\end{aligned}
$$

In Figure $2(\mathrm{e}, \mathrm{f})$ the mesh region of the face involute rack drive is illustrated.

\section{ANALYSIS OF THE GEOMETRY OF THE ACTIVE SURFACE OF THE FACE LINEAR RACK MECHANISMS}

In order to study analytically the geometric character of the action surface/mesh region of the face convolute rack mechanism, the system of equations (13) is presented in coordinate form [7]. Further in the study, the upper indices will be omitted. From the third equation of (13) it can be written:

$$
u= \pm \frac{z}{\cos \xi}, \text { i.e.: } U= \pm z \tan \xi-p_{t} \vartheta=f(z, U) .
$$

Let the first two equations of (13) together with the equation of meshing be solved:

$$
\begin{aligned}
& x=r_{0} \cos \theta-\frac{K \cdot j_{21} \cos \theta \sin \theta}{j_{21} \sin \theta+p_{t}}, \\
& y=r_{0} \sin \theta+\frac{K \cdot j_{21} \cos ^{2} \theta}{j_{21} \sin \theta+p_{t}} .
\end{aligned}
$$

Let $\sin \theta=t$ and $\cos ^{2} \theta=1-t^{2}$ be substituted into the second equation of (20) and the obtained quadratic equation be solved. Then:

$$
t_{1,2}=\frac{\left(j_{21} y-r_{0} p_{t}\right) \pm \sqrt{\left(j_{21} y-r_{0} p_{t}\right)^{2}-4 j_{21}\left(r_{0}-K\right)\left(j_{21} K+p_{t} . y\right)}}{2 j_{21}\left(r_{0}-K\right)},
$$

or more

$$
t_{1,2}=P_{1}(y) \pm \sqrt{P_{2}(y)},
$$

where $P_{1}(y)=\frac{j_{21} y-r_{0} p_{t}}{2 j_{21}\left(r_{0}-K\right)}, \quad P_{2}(y)=\left[\frac{j_{21} y-r_{0} p_{t}}{2 j_{21}\left(r_{0}-K\right)}\right]^{2}-\left(j_{21} K+p_{t} . y\right)$.

When the first equation of $(20)$ is multiplied with $\sin \theta$, and the second - with $\cos \theta$ and after summarizing it is obtained:

$$
x \sqrt{1-\left[P_{1}(y) \pm \sqrt{P_{2}(y)}\right]^{2}}+y\left[P_{1}(y) \pm \sqrt{P_{2}(y)}\right]=r_{0} .
$$

(c) Инженерни науки, год. LV, 2018, № 1 
The equation (23) describes a cylindrical surface with generatrices, parallel to the axis $O z$, which is the action surface of the face convolute rack mechanism.

For the case of face Archimedean rack drive, the equation (23) obtains the following form:

$$
x \sqrt{1-\left[P_{1}(y) \pm \sqrt{P_{2}(y)}\right]^{2}}+y\left[P_{1}(y) \pm \sqrt{P_{2}(y)}\right]=0,
$$

where $P_{1}(y)=\frac{y}{2 p_{t}}, P_{2}(y)=\frac{y}{2 p_{t}}+p_{t}\left(j_{21}+y\right)$.

The equality (24) describes analytically a cylindrical action surface of face Archimedean rack mechanism with generatrices, parallel to the axis $O z$.

Analogically, when in equation (23) the condition for evolving of the active tooth surfaces of the face involute worm is taken under consideration, then from the mesh region of the corresponding face rack mechanism, the following equation is obtained:

$$
\sqrt{j_{21}^{2}-p_{t}^{2}} \cdot x-p_{t} \cdot y-j_{21} \cdot r_{0}=0
$$

which is an equation of the plane parallel to the axis $O z$.

\section{CONCLUSION}

An important direction of contemporary "science of gear mechanisms" is the "geometric theory of gear transmissions". The basic tasks, which are solved by this direction of the science of gear mechanisms, are: development of adequate approaches to the synthesis and related to it active surfaces generation of different types gear transmissions; choice of rational form of active tooth surfaces; creation of a calculating apparatus for development of innovative drives and etc. In this work a calculating apparatus is presented, which is applicable in the synthesis of a new class of innovative rack drives with a special application for compact, highly accurate and highly loaded mechanical systems. Spatial rack drives are applicable in transmissions with a small translation motion.

\section{REFERENCES}

[1] E. Abadjieva, Mathematical Models of the Kinematic Processes in Spatial Rack Mechanisms and their Application, Ph. D. Thesis, Institute of Mechanics, Bulgarian Academy of Sciences, Sofia, Bulgaria (2009) 165.

(C) Инженерни науки, год. LV, 2018, № 1

(C) Engineering Sciences, LV, 2018, No. 1 
[2] V. Abadjiev, Gearing Theory and Technical Applications of Hyperboloid Mechanisms, D. Sc. Thesis, Institute of Mechanics, Bulgarian Academy of Sciences, Sofia, Bulgaria (2007) 309.

[3] E. AbadjIEva, Spatial Rack Drives, Mathematical Modelling for Synthesis, VDM Verlag Dr. Müller e.K. (2011) 72.

[4] F. Litvin, Theory of Gearing, NASA Reference Publication 1212, AVSCOM Technical Report 88-C-035, US Government Printing Office, Washington (1989) 470.

[5] F. Litvin, Gear Geometry and Applied Theory, PTR Prentice Hall, A Paramount Communication Company, Englewood Eliffs, New Jersey 07632 (1994) 724.

[6] F. Litvin And Al. Fuentes, Gear Geometry and Applied Theory, Second Edition, Cambridge University Press, Cambridge, New York, Melbourne, Madrid, Cape Town, Singapore, Sau Paulo, Delhi, Tokyo, Mexico City (2004) 800.

[7] P. Privalov, Analytical Geometry, 27 Edition, Gosudarstvenoe izdatelstvo fizikomatematicheskoi literaturi, Moscow (1962) 272.

\title{
ИЗСЛЕДВАНЕ НА ГЕОМЕТРИЯТА НА ПРОСТРАНСТВЕН ГРЕБЕНЕН МЕХАНИЗЪМ С ЧЕЛНО ЗАЦЕПЕНИ ПОДВИЖНИ ЗВЕНА ЧАСТ II. СИНТЕЗ НА ПОВЪРХНИНАТА НА ЗАЦЕПВАНЕ И НА АКТИВНИТЕ ЗЪБНИ ПОВЪРХНИНИ НА ИЗВЪРШВАЩО ПРАВОЛИНЕЙНА ТРАНСЛАЦИЯ ЗВЕНО
}

\author{
ЕМИЛИЯ АБАДЖИЕВА \\ Институт по механика, \\ Бблгарска академия на науките, \\ Акад. Г. Бончев, бл. 4, 1113 София, Бглгария, \\ e-mail: abadjieva@gipc.akita-u.co.jp; abadjieva@gmail.com \\ Резюме. Важен клон на съвременната „наука за зббните ме- \\ ханизми“ е „геометричната теория на згбните трансми- \\ сии". Основните задачи, които решава този клон от науката \\ за зъбните механизми, са: разработване на адекватни подходи \\ за синтез и свързаното с него генериране на активните зъб- \\ ни повърхнини на различни типове зъбни задвижвания; избор \\ на рационална форма на активните зъбни повърхнини; съз- \\ даване на изчислителен апарат за формиране на иновативни \\ задвижвания и пр.
}

(c) Инженерни науки, год. LV, 2018, № 1

29

(c) Engineering Sciences, LV, 2018, No. 1 
В тази втора част на изследването са представени аналитични зависимости, дефиниращи основните геометрични характеристики на равнината на зацепване и активните зъбни повърхнини на извършващото линейно преместване подвижно звено на гребенните механизми. Разгледани са случаите, когато активните зъбни повърхнини на ротиращото звено, дефинирани аналитично в първата част на изследването, са челни конволютни, архимедови и еволвентни винови повърхнини с постоянна стъпка. В тази работа е представен изчислителен апарат, приложим при синтеза на нов клас иновативни гребенни задвижвания със специално приложение за компактни, високо точни и високо натоварени механични системи. Пространствените челни гребенни механизми са приложими като задвижвания с малък работен ход.

Ключови думи: гребенен механизъм, математично моделиране, синтез, челен линеен хеликоид, повърхнина на зацепване, поле на зацепване.

Received October 05, 2017 